\title{
The importance of dietary polyamines in cell regeneration and growth
}

\author{
BY SUSAN BARDÓCZ, TRACEY J. DUGUID, DAVID S. BROWN, GEORGE \\ GRANT, ARPAD PUSZTAI, ANN WHITE AND ANN RALPH \\ The Rowett Research Institute, Bucksburn, Aberdeen AB2 9SB
}

(Received 8 July 1994-Received 6 October 1994-Accepted 10 October 1994)

\begin{abstract}
The polyamines putrescine, spermidine and spermine are essential for cell renewal and, therefore, are needed to keep the body healthy. It was previously believed that polyamines are synthesized by every cell in the body when required. However, in the present paper evidence is provided to show that, as in the case of the essential amino acids, the diet can supply sufficient amounts of polyamines to support cell renewal and growth. Systematic analysis of different foods was carried out and from the data obtained, the average daily polyamine consumption of British adults was calculated to be in the range 350-500 $\mathrm{\mu mol} /$ person per $d$. The major sources of putrescine were fruit, cheese and non-green vegetables. All foods contributed similar amounts of spermidine to the diet, although levels were generally higher in green vegetables. Meat was the richest source of spermine. However, only a part of the polyamines supplied by the diet is available for use by the body. Based on experiments with rats it was established that polyamines were readily taken up from the gut lumen, probably by passive diffusion, and were partly metabolized during the process of absorption. More than $80 \%$ of the putrescine was converted to other polyamines and non-polyamine metabolites, mostly to amino acids. The enzyme responsible for controlling the bioavailability of putrescine was diamine oxidase $(E C$ 1.4.3.6). For spermidine and spermine, however, about $\mathbf{7 0 - 8 0 \%}$ of the intragastrically intubated dose remained in the original form. Considering the limitations on bioavailability (metabolism and conversion), the amounts of polyamines supplied by the average daily diet in Britain should satisfy metabolic requirements.
\end{abstract}

Polyamines: Bioavailability: Cell regeneration

Polyamines are ubiquitous molecules that occur in every living cell. They fulfil an array of roles in cellular metabolism (Tabor \& Tabor, 1984; Pegg, 1986) and are involved in many steps of protein, RNA and DNA synthesis, from the control and initiation of translation (Konecki et al. 1975); regulation of its fidelity (Abraham et al. 1979); stimulation of ribosome subunit association (Kyner et al. 1973), through enhancement of RNA(Barbiroli et al. 1971) and DNA synthesis (Fillingame et al. 1975); stabilization of the structure of tRNA (Cohen, 1978) and reduction of the rate of RNA degradation (Fausto, 1972); and involvement in the condensation of DNA (Anderson \& Norris, 1960), to the covalent modification of proteins (Williams-Ashman \& Canellakis, 1979). Although some of the biological effects of polyamines are specific, they interact non-specifically with negatively charged structures of cells or neutralize membranes (Schuber, 1989). In these non-specific roles polyamines can be replaced by metal ions, most often by $\mathrm{Mg}^{2+}$ or $\mathrm{Ca}^{2+}$. Because of their specificity, polyamines are essential for growth and cell proliferation. However, their most important function, which cannot be replaced by any of the other positively charged molecules, is as mediators of the action of all known hormones and growth factors.

In the past it was believed that polyamines were synthesized in situ in the cells when required. However, as more and more information is gathered the importance of 
polyamines from extracellular sources, particularly the diet or bacteria resident in the gastrointestinal tract, is increasingly recognized (Osborne \& Seidel, 1989; Sarhan et al. 1989; Molinoux et al. 1991). In spite of the undoubted importance of polyamines in growth, little information is available in nutritional handbooks on the polyamine content and composition of even the most common foods. Analysis of some of the most important of these showed that a 'normal' diet can contain relatively large amounts of polyamines (Bardócz et al. 1993). However, the amounts of polyamines consumed daily by an adult and how much of these can be absorbed and made available for utilization by the human body are not known.

With information obtained from the British National Food Survey (Ministry of Agriculture, Fisheries and Food, 1992), the daily average dietary intake for adults was calculated using our analytical data of polyamine concentrations in different foods. As there is a scarcity of information on the bioavailability and mechanism of polyamine uptake by the gut and the fate of polyamines derived from the gut lumen in humans, growing rats were used as a model to study the absorption and conversion/catabolism of polyamines in the intestinal lumen.

\section{MATERIALS AND METHODS}

\section{Food polyamine analysis}

Various types of raw and cooked foods were obtained from the Institute's kitchens or bought from supermarkets. The selection was based on the common foods or food groups in the British diet as listed in the National Food Survey (Ministry of Agriculture, Fisheries and Food, 1992). Some food items were sampled individually, e.g. beef and milk, while for others, such as breakfast cereals and crisps, several varieties were mixed together in equal quantities and a sample of the mixture was taken for analysis. Only one sample was obtained for most of the foods analysed. This was divided into four subsamples (1.0-1.5 $\mathrm{g}$ or $\mathrm{ml}$ ) which were prepared for analysis as reported by Bardócz et al. (1993) and the polyamine concentrations determined by HPLC (Seiler \& Knödgen, 1980). The sensitivity of the assay, allowing for dilution and recovery, was $0 \cdot 1-0.2 \mathrm{nmol}$ polyamine $/ \mathrm{ml}$ for liquid food and 50-60 nmol polyamine/100 $\mathrm{g}$ for 'solid' food.

\section{Calculation of daily food intake}

British adults. The National Food Survey is published annually by the Ministry of Agriculture, Fisheries and Food (MAFF) and provides a wealth of detailed information on household food consumption for different regions of Britain, for different seasons, income groups, family composition etc. We have used data on the national average consumption of foods given as ounces/person per week (Ministry of Agriculture, , Fisheries and Food, 1992) and converted it to $\mathrm{g}$ /person per $\mathrm{d}$ for each food group. Over 165 different foods are listed in the MAFF tables and some categories are given supplementary classification. For example, the cereal category includes seven types of bread and sixteen cereals in the main table. A supplementary table includes five more types of bread and seven further categories of cereal. Cereals include cakes, pastries, biscuits and puddings as well as breakfast cereals, rice and pasta.

We did not analyse all the different foods for polyamine content but only the ones which were thought to be the most representative for each group. Some of these data were presented by Bardócz et al. (1993), and further analyses are given in Table 1. For example, in the bread group we analysed wholemeal and white bread separately, and then used the average of these values in Table 2. Similarly, fresh apples, oranges and pears were analysed separately and an average value taken for the fresh fruit classification (Table 2). Not every vegetable variety was sampled; green vegetables comprised equal proportions of cabbage, 
Table 1. Polyamine content (nmol/g or $\mathrm{ml}$ ) of some foods consumed by adults

(Range values for four samples)

\begin{tabular}{|c|c|c|c|}
\hline Food type & Putrescine & Spermidine & Spermine \\
\hline $\begin{array}{l}\text { Cereals } \\
\text { Mixed breakfast cereals (ten varieties) } \\
\text { Jam tart } \\
\text { Sponge pudding } \\
\text { Custard }\end{array}$ & $\begin{array}{l}23-25 \\
10-12 \\
8-12 \\
2-4\end{array}$ & $\begin{array}{c}166-168 \\
27-31 \\
17-23 \\
*\end{array}$ & $\begin{array}{c}30-33 \\
1-2 \\
1-3 \\
*\end{array}$ \\
\hline$\underset{\text { Boiled }}{\text { Egg }}$ & $3-4$ & $0-1$ & $1-3$ \\
\hline $\begin{array}{l}\text { Vegetable products } \\
\text { Lentil soup } \\
\text { Potato crisps (three varieties) } \\
\text { Chips }\end{array}$ & $\begin{array}{c}38-39 \\
436-476 \\
240-250\end{array}$ & $\begin{array}{l}148-155 \\
243-275 \\
164-178\end{array}$ & $\begin{array}{l}34-39 \\
21-25 \\
12-14\end{array}$ \\
\hline $\begin{array}{l}\text { Fruit products } \\
\text { Mandarin orange, raw } \\
\text { Peach, canned } \\
\text { Pears, canned } \\
\text { Raisins }\end{array}$ & $\begin{array}{r}13-15 \\
13-15 \\
10-12 \\
9-14\end{array}$ & $\begin{array}{r}18-20 \\
15-19 \\
21-25 \\
6-11\end{array}$ & $\begin{array}{l}2-3 \\
1 \\
2-4 \\
2-3\end{array}$ \\
\hline $\begin{array}{l}\text { Nuts } \\
\text { Cashew nuts }\end{array}$ & $182-185$ & $255-266$ & $265-279$ \\
\hline $\begin{array}{l}\text { Meat } \\
\text { Beef, raw } \\
\text { Beef, cooked } \\
\text { Irish stew (lamb, cooked) } \\
\text { Sweet and sour pork (pork, cooked) }\end{array}$ & $\begin{array}{l}169-187 \\
56-58 \\
21-23 \\
251-263\end{array}$ & $\begin{array}{l}19-21 \\
26-28 \\
55-62 \\
45-51\end{array}$ & $\begin{array}{l}175-197 \\
104-122 \\
73-78 \\
56-64\end{array}$ \\
\hline $\begin{array}{l}\text { Fish } \\
\text { Fish in cheese sauce }\end{array}$ & $55-66$ & $20-24$ & $16-19$ \\
\hline $\begin{array}{l}\text { Sugar and preserves } \\
\text { Sugar (three varieties) } \\
\text { Jam (four varieties) }\end{array}$ & $\stackrel{*}{13-15}$ & $\begin{array}{c}1-2 \\
12-18\end{array}$ & $\stackrel{*}{4-13}$ \\
\hline $\begin{array}{l}\text { Beverages } \\
\text { Tea: Leaves } \\
\text { Infusion } \\
\text { Coffee: Granules } \\
\text { Infusion }\end{array}$ & $\begin{array}{c}164-183 \\
* \\
33-37 \\
0-1\end{array}$ & $\begin{array}{c}252-274 \\
1-2 \\
18-24 \\
*\end{array}$ & 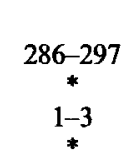 \\
\hline
\end{tabular}

* Below the level of detection.

peas, green beans and cauliflower, other vegetables were represented by carrots, onions, tomatoes and mushrooms. Using this method we calculated the polyamine intake from typical foods in each group and used either an average value or the appropriate proportional values according to their proportion in the diet. These data are given in Table 2.

Animals. Male Hooded-Lister rats (about $80 \mathrm{~g}$ ) were prefed with a powdered lactalbumin (La) diet for $3 \mathrm{~d}$ (Bardócz et al. 1990 a). After overnight fasting, rats were given $1.5 \mathrm{~g}$ of the La diet. Immediately after this was eaten (about $2 \mathrm{~min}$ ) they were given, by intragastric intubation, a mixture of a standard amount (about $10 \mathrm{nmol}$ ) of the appropriate ${ }^{14} \mathrm{C}$-labelled polyamine $\left(8.5 \mathrm{nmol}, 2.4 \times 10^{6}\right.$ disintegrations/min $(\mathrm{dpm})$ per rat, ${ }^{14} \mathrm{C}$-labelled putrescine; $9.9 \mathrm{nmol}, 3.3 \times 10^{6} \mathrm{dpm} / \mathrm{rat}$, ${ }^{14} \mathrm{C}$-labelled spermidine; $9.9 \mathrm{nmol}, 3.0 \times 10^{6} \mathrm{dpm} / \mathrm{rat}$, ${ }^{14} \mathrm{C}-$ labelled spermine; Amersham International Plc, Amersham, Bucks in phosphate-buffered saline (Bardócz et al. $1990 \mathrm{a}$ ) and either $0.1,1.0$ or $5.0 \mathrm{mg}$ of the individual unlabelled polyamine. These quantities $(0 \cdot 1,1.0$ or $5.0 \mathrm{mg})$ corresponded to 630,6200 or $31000 \mathrm{nmol}$ 
Table 2. Food polyamine content for the average adult daily intake in Britain

\begin{tabular}{lrrrr}
\hline \hline Food & $\begin{array}{r}\text { Intake } \\
(\mathrm{g} / \mathrm{d})\end{array}$ & $\begin{array}{c}\text { Putrescine } \\
(\mathrm{nmol})\end{array}$ & $\begin{array}{c}\text { Spermidine } \\
\text { (nmol) }\end{array}$ & $\begin{array}{c}\text { Spermine } \\
\text { (nmol) }\end{array}$ \\
\hline Bread & $107 \cdot 3$ & 1449 & 12124 & 3112 \\
Other cereal & $207 \cdot 5$ & 2542 & 6121 & 10686 \\
Milk, cream, yoghurt (ml/d) & $303 \cdot 5$ & 405 & 759 & 531 \\
Cheese & $16 \cdot 6$ & 62989 & 16853 & 2594 \\
Eggs & $16 \cdot 1$ & 48 & 0 & 32 \\
Potatoes & $136 \cdot 9$ & 33540 & 14375 & 3559 \\
Green vegetables & $37 \cdot 0$ & 1665 & 8834 & 5134 \\
Vegetables (other) & $65 \cdot 9$ & 25141 & 2274 & 395 \\
Canned, frozen vegetables & $77 \cdot 8$ & 3190 & 16571 & 10503 \\
Fresh fruit & $87 \cdot 2$ & 46754 & 12993 & 4127 \\
Fruit products & $46 \cdot 6$ & 28700 & 584 & 0 \\
Sugar, jam & $31 \cdot 1$ & 217 & 280 & 124 \\
Oils, fats & $35 \cdot 5$ & na & na & na \\
Red meat & $45 \cdot 6$ & 1402 & 1596 & 8835 \\
Meat products & $62 \cdot 9$ & 6494 & 2390 & 9372 \\
Poultry & $28 \cdot 9$ & 939 & 1850 & 8468 \\
Fish & $19 \cdot 8$ & 3351 & 381 & 490 \\
Beverages & $10 \cdot 1$ & 0 & 0 & 0 \\
Nuts & $2 \cdot 1$ & 386 & 550 & 569 \\
Total (approximately) & 1338 & 220000 & 99000 & 69000 \\
\hline
\end{tabular}

na, not possible to analyse.

putrescine; 400,3900 or $19600 \mathrm{nmol}$ spermidine; 300,2900 or $14400 \mathrm{nmol}$ spermine. Rats were killed by diethyl ether anaesthesia exactly $1 \mathrm{~h}$ later, their small intestine was removed and washed with ice-cold saline $(9 \mathrm{~g} \mathrm{NaCl} / 1)$. These washings were collected and the radioactivity measured. The concentration of polyamine incorporated into the rat body $1 \mathrm{~h}$ after intubation was calculated as the amount intubated minus that found in the luminal contents. Radioactivity was also measured according to the method of Bardócz et al. (1992) in the liver, kidney, left hind leg gastrocnemius muscle, skin, spleen, thymus, lungs, pancreas, stomach, caecum, colon, sections of the small intestine and blood, and percentage of radioactivity in the 'whole body' was similar to the value obtained by implied difference. An average absorption for the rat $1 \mathrm{~h}$ after gastric intubation of $9.9 \mathrm{nmol}{ }^{14} \mathrm{C}$-labelled spermidine was as follows (values are pmol spermidine) : liver 1600 , spleen 20 , pancreas 100 , colon 160 , caecum 120 , small intestine 880 , stomach 120 , blood $15 \mathrm{pmol} / \mathrm{ml}$, kidney 190 , lungs 50 , gastrocnemius muscle 40 , stomach contents 20 , small intestine contents 260 , caecum contents 220 , colon contents 80 .

To follow the absorption of the polyamines, sections $(180 \mathrm{~mm})$ of jejunum $(70-250 \mathrm{~mm}$ from the pylorus end) from two rats per treatment group were homogenized in perchloric acid $(20 \mathrm{ml} / \mathrm{l})$, centrifuged and the polyamine concentrations determined by HPLC (Seiler \& Knödgen, 1980). Samples (450 $\mu \mathrm{l}$, containing $1800-3000 \mathrm{dpm})$ obtained from the homogenates were analysed by HPLC to identify the radioactive polyamines or their derivatives. Fractions $(n 45)$ were collected per sample and the radioactivity measured.

\section{RESULTS}

Polyamine analyses of foods: daily dietary intake

The results of foods analysed for polyamine content in addition to those given in Bardócz et al. (1993) are shown in Table 1. The list of food groups which make up the average daily intake for adults in Britain and their polyamine concentration are listed in Table 2. Over 

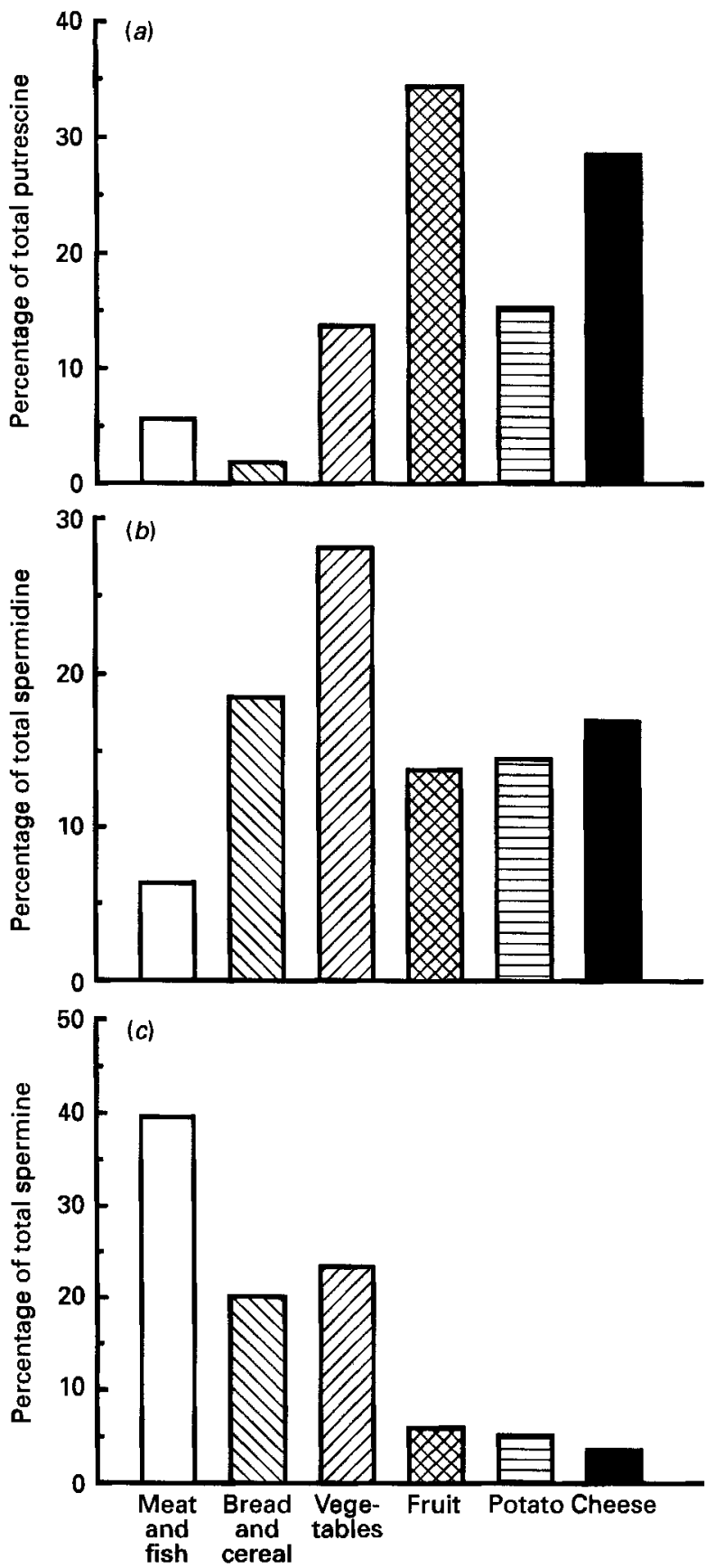

Fig. 1. Sources of (a) putrescine, (b) spermidine and (c) spermine in the average diet of British adults expressed as a percentage of the total individual polyamine value given in Table 2.

half the polyamine intake was as putrescine (57\%), with spermidine and spermine accounting for 26 and $18 \%$ respectively. There was, however, a wide variation in the concentration of polyamines in different foods. Dairy products had generally low levels of polyamines, with the exception of cheese, a product of microbial fermentation. Green 

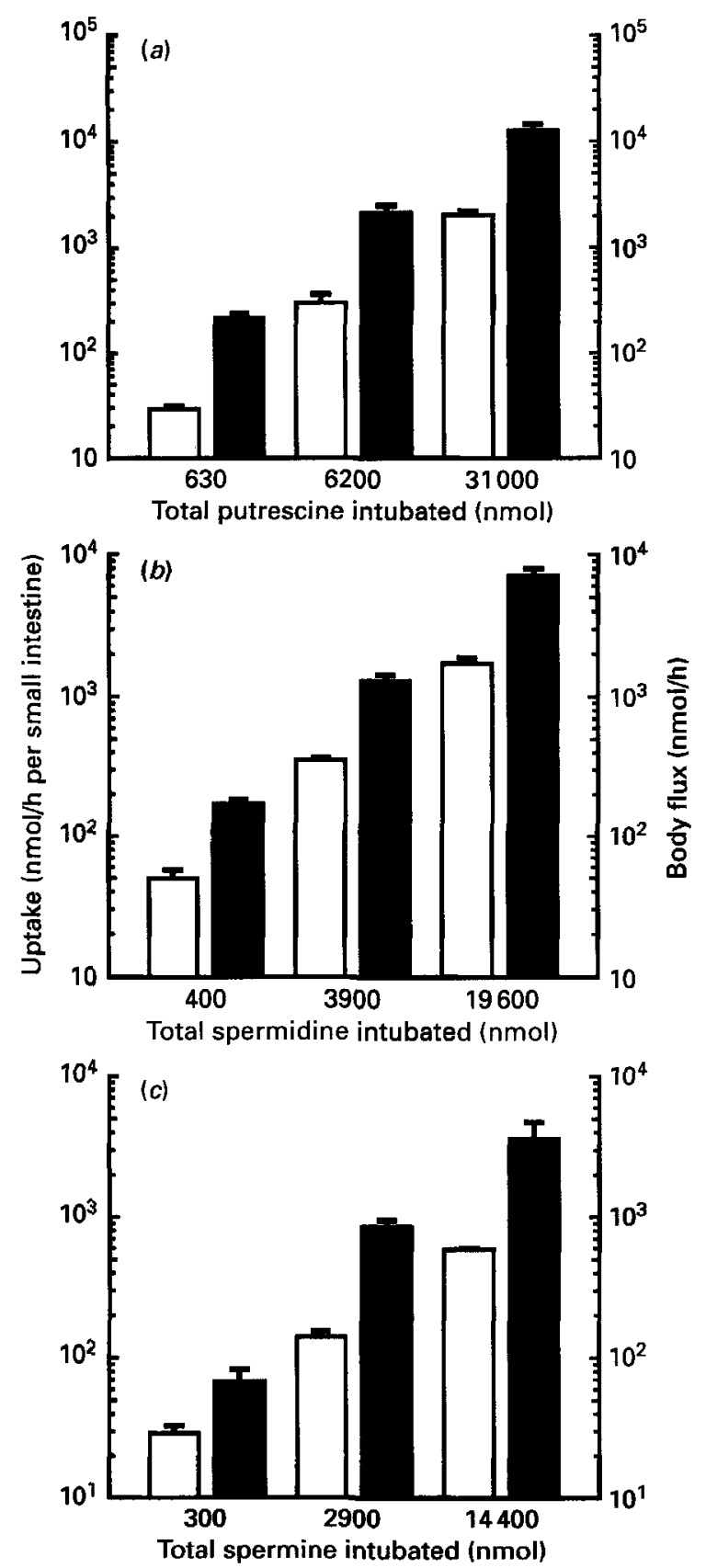

Fig. 2. Luminal uptake by the small intestine ( $\square$ ) and body flux $(\mathbf{n} ; \mathrm{nmol} / \mathrm{h})$ of (a) putrescine, (b) spermidine and (c) spermine of lactalbumin-fed rats $1 \mathrm{~h}$ after intragastric intubation of different mixtures of unlabelled and ${ }^{14} \mathrm{C}$-labelled polyamine. For details of procedures, see pp. 821-822. Values are means with their standard errors represented by vertical bars.

vegetables were high in spermidine, whereas potatoes and other vegetables were high in putrescine, as were fruit and fish. Red meat and poultry, however, were high in spermine. Values for the percentage contribution of different groups of food to the total polyamine concentration in the diet are shown in Fig. 1. 
(a)

$$
18-24 \% \text { recovered }
$$
as other polyamines

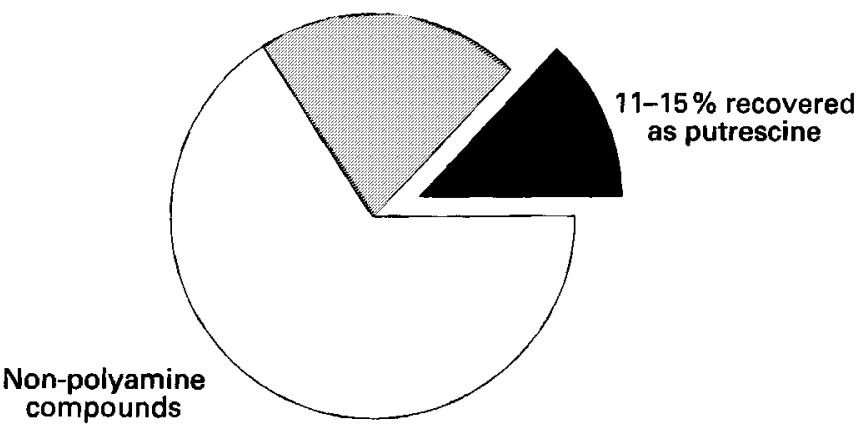

(b)

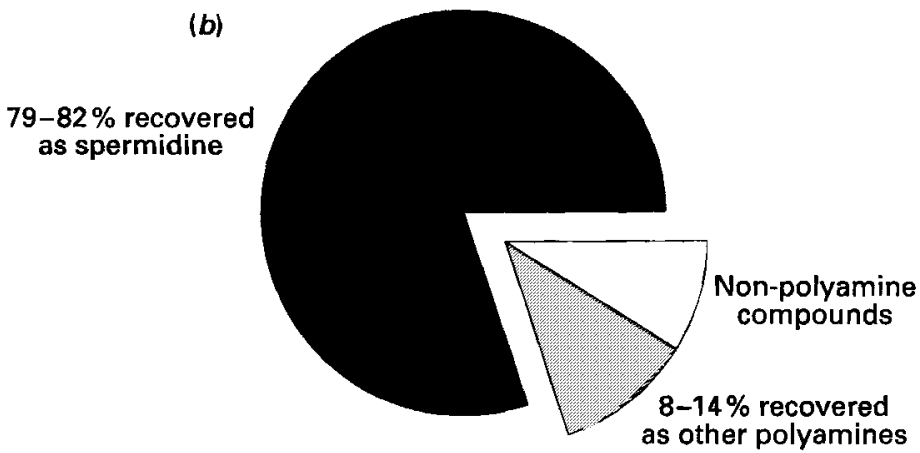

(c)

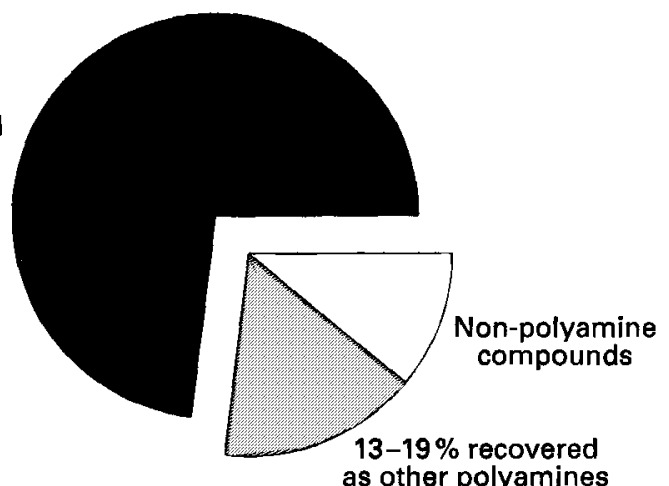

Fig. 3. Recovery as a percentage of the dose absorbed by the jejunal tissue of radioactive polyamines $1 \mathrm{~h}$ after the administration of (a) ${ }^{14} \mathrm{C}$-labelled putrescine, (b) spermidine or (c) spermine by intragastric intubation.

\section{Absorption and conversion of polyamines}

The uptake of polyamines by the small intestine was apparently linearly dependent on the total input (Fig. 2). After $1 \mathrm{~h}$ intragastric intubation 4-12\% of the total labelled putrescine was found in the small-intestinal tissue and about $35-43 \%$ had passed into the body. Similar values were found for spermidine (8-13 and 34-44\%). However, although the amount of labelled spermine in the small-intestinal tissue was in the same range (4-10\%), that found in the body was only $23-31 \%$.

The percentage recovery of the polyamines after the $1 \mathrm{~h}$ experimental period showed that two-thirds of the labelled putrescine absorbed by the small intestine was converted to non- 
polyamine type compounds and only $11-15 \%$ was recovered as putrescine (Fig. 3(a)). However, most of the spermidine (79-82\%) and spermine (72-74\%) remained in the form given (Fig. 3(b and c)).

\section{DISCUSSION}

Based on new analytical data (Table 1) and those published earlier from our laboratory (Bardócz et al. 1993), it is evident that all types of food, whether it is of plant (vegetables and fruit) or animal origin (milk, eggs, meat), contain polyamines. On the basis of these data the average daily polyamine intake by an adult in Britain can be calculated and it becomes evident that a typical diet could supply hundreds of $\mu \mathrm{mol}$ polyamines $/ \mathrm{d}$. We are aware that until all foods have been analysed and a larger sample of foods obtained from different sources, including different brands and varieties, the values given in Table 2 are only a first approximation of possible levels of polyamines in the British adult diet.

It appears from our data that polyamines can readily be taken up from the gut lumen, probably by passive diffusion, at least in the concentration range studied. It is possible that there are other mechanisms for absorption, such as active transport or facilitated diffusion. However, based on in vitro studies with cells (Scemama et al. 1993) these transport systems are operational at much lower luminal polyamine concentrations than those found in normal diets. Thus, their importance in absorption of the dietary polyamines is questionable. Using radiolabelled polyamines we were able to demonstrate that up to one half of the intubated dose of the luminal polyamines was absorbed into the systemic circulation and distributed within the different organs of the body during the first hour. However, the distribution was not even, as the counts accumulated had no correlation with the weight of the individual organs, but rather reflected their metabolic activity (Bardócz et al. 1992).

A variable proportion of the food polyamines was converted by the action of gut enzymes to polyamine- and/or non-polyamine metabolites during passage through the intestine. Thus, the true amounts of polyamines reaching the body are different for individual polyamines. Of the catabolic enzymes, diamine oxidase ( $E C$ 1 .4 3.3.6; Baylin et al. 1978) and polyamine oxidase (EC 1.5.3.11; Höltta, 1977; Seiler et al. 1980) seem to be the most important in limiting the availability of polyamines for absorption. For example, $1 \mathrm{~h}$ after rats were intubated with ${ }^{14} \mathrm{C}$-labelled putrescine, only $29-39 \%$ of the label was found as polyamines of which putrescine contributed $11-15 \%$. This intensive breakdown of putrescine is probably the result of the action of diamine oxidase, which is one of the most abundant enzymes in the intestinal tissue (Höltta, 1977; Seiler et al. 1980). In contrast, $79 \%$ labelled spermidine and 72-74\% labelled spermine remained in the rat body $1 \mathrm{~h}$ after intubation in the same form as given and, if conversion to the other two natural polyamines is taken into account, $87-96 \%$ of the radioactive spermidine and $79-82 \%$ of the spermine were retained in polyamine form. Accordingly, as spermidine and spermine were well conserved for further utilization in the body, they are the 'right' polyamines to be absorbed from food as opposed to putrescine, which is mostly converted to non-polyamine metabolites.

On the basis of these observations the diet provides large enough quantities of polyamines (relative to biosynthesis, which is about $1-2 \mathrm{nmol} / \mathrm{h}$ per $\mathrm{g}$ wet tissue in the most active organs) for absorption and contribution to the polyamine pool through the systemic circulation, thereby reaching every tissue of the body. This could be nutritionally and metabolically important, providing that dietary polyamines are as readily absorbed by the human small intestine and can be passed into the systemic circulation as has been found with rats (Bardócz et al. $1990 a, b$ ).

The importance of dietary polyamines in growth and health probably changes with the 
physiological or pathological state of the person. Polyamine requirements are higher in the young during intensive growth. Although these can be satisfied to some extent by the more active biosynthesis, polyamines supplied by the diet have an important role to play. In healthy adults the polyamine requirement will not be high because polyamines are only needed in the replacement of some cells, and to mediate hormone/growth factor action. Cell proliferation slows down with age, when the activity of ornithine decarboxylase (EC 4.1.1.17) also diminishes, therefore dietary polyamines may play a significant role later in life.

In pathological states when inhibition of unwanted growth, such as neoplastic proliferation of tissues, is desirable, the intake of polyamines should perhaps be minimized in an attempt to slow down the growth and progression of the tumour. To the best of our knowledge this type of dietary control of tumour growth has not yet been attempted in man. In contrast, during periods where intensive growth is required, such as in wound healing, post-operational recovery, liver regeneration and compensatory growth of the lung or the gut, dietary polyamines have a major role to play in promoting cell regeneration.

In summary, although every cell has the capacity to synthesize some polyamines, the body also relies on a continuous supply of polyamines from the food. Thus, polyamine requirements which cannot be met by biosynthesis have ultimately to be satisfied from exogenous sources, the most important of which is the diet.

This work was financed by the Scottish Office Agriculture and Fisheries Department and is also a part of the EEC Concerted Action Programmes AIR 569/92 and FLAIR No. 9.

\section{REFERENCES}

Abraham, A. K., Olsner, S. \& Phil, A. (1979). Fidelity of protein synthesis in vitro is increased in the pancreas in the presence of spermidine. FEBS Letters 101, 93-96.

Anderson, N. G. \& Norris, C. B. (1960). The effects of amines on the structure of isolated nuclei. Experimental Cell Research 19, 605-618.

Barbiroli, B., Corti, A. \& Caldarera, C. M. (1971). The pattern of synthesis of ribonucleic acid species under the action of spermine in the chick embryo. Biochemical Journal 123, 123-124.

Bardócz, S., Brown, D. S., Grant, G. \& Pusztai, A. (1990a). Luminal and basolateral polyamine uptake by rat small intestine stimulated to grow by Phaseolus vulgaris lectin phytohaemagglutinin in vivo. Biochimica et Biophysica Acta 1034, 46-52.

Bardócz, S., Brown, D. S., Grant, G., Pusztai, A., Stewart, J. C. \& Palmer, R. M. (1992). Effect of the $\beta$ adrenoceptor agonist clenbuterol and phytohaemagglutinin on growth, protein synthesis and polyamine metabolism of tissues of the rat. British Journal of Pharmacology 106, 476-482.

Bardócz, S., Grant, G., Brown, D. S., Ewen, S. W. B., Nevison, I. \& Pusztai, A. (1990 b). Polyamine metabolism and uptake during Phaseolus vulgaris lectin, PHA-induced growth of rat small intestine. Digestion 46, Suppl. 2, 360-366.

Bardócz, S., Grant, G., Brown, D. S., Ralph, A. \& Pusztai, A. (1993). Polyamines in food-implications for growth and health. Journal of Nutritional Biochemistry 4, 66-71.

Baylin, S. B., Stevens, S. A. \& Mohamad-Sakir, K. M. (1978). Association of diamine oxidase and ornithine decarboxylase with maturing cells in rapidly proliferating epithelium. Biochimica et Biophysica Acta 541, $415-419$.

Cohen, S. S. (1978). What do the polyamines do? Nature 274, 209-210.

Fausto, N. (1972). RNA metabolism in isolated perfused normal and regeneration livers: polyamine effects. Biochimica et Biophysica Acta 281, 543-553.

Fillingame, R. H., Jorstad, C. M. \& Morris, D. R. (1975). Increased cellular levels of spermidine or spermine are required for optimal DNA synthesis in lymphocytes activated by concanavalin A. Proceedings of the National Academy of Sciences USA 72, 4042-4046.

Höltta, E. (1977) Oxidation of spermidine and spermine in rat liver: purification and properties of polyamine oxidase. Biochemistry 16, 91-100.

Konecki, D., Kramer, G., Pinphanichakarn, P. \& Hardesty, B. (1975). Polyamines are necessary for maximum in vitro synthesis of globin peptides and play a role in chain initiation. Archives of Biochemistry and Biophysics 169 , 192-198. 
Kyner, D., Zabros, P. \& Levin, D. H. (1973). Inhibition of protein chain initiation in eukaryotes by deacetylated transfer RNA and its reversibility by spermine. Biochimica et Biophysica Acta 324, 386-396.

Ministry of Agriculture, Fisheries and Food (1992). National Food Survey, Annual Report on Household Food Consumption and Expenditure. London: H.M. Stationery Office.

Molinoux, J.-P., Darcel, F., Quemener, V., Havouis, R. \& Seiler, N. (1991). Inhibition of the growth of U-251 human glioblastoma in nude mice by polyamine deprivation. Anticancer Research 11, 175-180.

Osborne, D. L. \& Seidel, E. R. (1989). Microflora-derived polyamines modulate obstruction-induced colonic mucosal hypertrophy. American Journal of Physiology 256, G1049-G1057.

Pegg, A. E. (1986). Recent advances in the biochemistry of polyamines in eukaryotes. Biochemical Journal 234, 249-262.

Sarhan, S., Knödgen, B. \& Seiler, N. (1989). The gastrointestinal tract as polyamine source for tumor growth. Anticancer Research 9, 215-224.

Scemama, J.-L., Grabié, V. \& Seidel, E. R. (1993). Characterization of univectorial polyamine transport in duodenal crypt cell line. American Journal of Physiology 265, G851-G856.

Schuber, F. (1989). Influence of polyamines on membrane function. Biochemical Journal 260, 1-10.

Seiler, N., Bolkenius, F. N., Knödgen, B. \& Mammont, P. (1980). Polyamine oxides in rat tissues. Biochimica et Biophysica Acta $615,480-488$.

Seiler, N. \& Knödgen, B. (1980). High-performance liquid chromatography procedure for the simultaneous determination of natural polyamines and their monoacetyl derivatives. Journal of Chromatography 221, 227-235.

Tabor, C. W. \& Tabor, H. (1984). Polyamines. Annual Review of Biochemistry 53, 747-790.

Williams-Ashman, H. G. \& Canellakis, Z. N. (1979). Polyamines in mammalian biology and medicine. Perspectives in Biology and Medicine 22, 421-453. 